\title{
Erratum to: Patient preferences for treatment of castration-resistant prostate cancer in Japan: a discrete-choice experiment
}

Hiroji Uemura ${ }^{1}$, Nobuaki Matsubara², Go Kimura ${ }^{3}$, Akito Yamaguchi ${ }^{4}$, Dianne Athene Ledesma ${ }^{5}$, Marco DiBonaventura ${ }^{6}$, Ateesha F. Mohamed ${ }^{7}$, Enrique Basurto ${ }^{6}$, lan McKinnon ${ }^{6}$, Ed Wang ${ }^{7}$, Kristen Concialdi ${ }^{6}$, Aya Narimatsu ${ }^{5}$ and Yasuko Aitoku ${ }^{5^{*}}$

\section{Erratum}

After publication of this work [1] it was noticed that there was a typographical error in the Conclusions. The letter 'a' in 'asymtoptomatic' should have been removed in the concluding statement as it is inconsistent with the Results and Discussion. The statement in the Conclusions should read: 'Patients who were symptomatic placed significantly more importance on delaying an SSE when expressing medication preferences.'

The original article was corrected. The publisher apologises for this error.

\footnotetext{
Author details

'Department of Urology and Renal Transplantation, Yokohama City University Medical Center, Yokohama, Japan. ${ }^{2}$ Division of Breast and Medical Oncology, National Cancer Center Hospital East, Chiba, Japan. ${ }^{3}$ Department of Urology, Nippon Medical School, Tokyo, Japan. ${ }^{4}$ Division of Urology, Harasanshin General Hospital, Fukuoka, Japan. ${ }^{5}$ Bayer Yakuhin, Ltd., 2-4-9, Umeda, Kita-ku, Osaka 530-0001, Japan. ${ }^{6}$ Kantar Health, New York, NY, USA. ${ }^{7}$ Bayer Healthcare, Whippany, NJ, USA.
}

Received: 21 March 2017 Accepted: 21 March 2017

Published online: 28 March 2017

\section{Reference}

1. Uemura H, Matsubara N, Kimura G, Yamaguchi A, Ledesma DA,

DiBonaventura $\mathrm{M}$, et al. Patient preferences for treatment of castrationresistant prostate cancer in Japan: a discrete-choice experiment. BMC Urol. 2016;16:63.

\footnotetext{
* Correspondence: yasuko.aitoku@bayer.com

${ }^{5}$ Bayer Yakuhin, Ltd., 2-4-9, Umeda, Kita-ku, Osaka 530-0001, Japan
} 